\title{
BERTUMBUH DALAM RELASI DENGAN KRISTUS BERDASARKAN KOLOSE 2:6-7
}

\author{
Sion Saputra, ${ }^{1}$ Hana Suparti, ${ }^{2}$ Talizaro Tafonao ${ }^{3}$ \\ Sekolah Tinggi Teologi KADESI Yogyakarta, ${ }^{1,2}$ Universitas Kristen Indonesia Jakarta ${ }^{3}$ \\ sionsaputra04@gmail.com, ${ }^{1}$ hanakadesi@yahoo.com, ${ }^{2}$ talizarotafonao@gmail.com ${ }^{3}$
}

\begin{abstract}
Abstrak
Dalam artikel ini, penulis melakukan kajian mengenai bertumbuh dalam relasi dengan Kristus berdasarkan Kolose 2:6-7. Atikel ini beranjak dari kegelisahan penulis terhadap kondisi dangkalnya iman orang percaya saat ini, di mana dengan mudahnya terhisap oleh ajaran-ajaran palsu yang marak beredar di media-media sosial. Perkembangan ilmu dan teknologi memudahkan orang Kristen untuk mendapatkan berbagai ajaran yang telah ada di media sosial yang tidak berdasarkan firman Tuhan. Tujuan dari penulisan ini ialah menyuguhkan hasil kajian mengenai bagaimana cara orang percaya bertumbuh dalam relasi dengan Kristus. Artikel ini menganalisis mengenai bertumbuh dalam relasi dengan Kristus berdasarkan Kolose 2:6-7, agar nasihat Paulus kepada jemaat di Kolose juga dapat dilakukan oleh jemaat masa kini. Metode yang penulis gunakan dalam artikel ini adalah metode penelitian kualitatif dengan pendekatan eksegese. Proses analisis yang dilakukan penulis adalah mengesegese teks Alkitab dan menganalisis sumber-sumber sekunder yang terpercaya untuk menghasilkan kajian yang dapat dipertanggungjawabkan. Hasil dari kajian ini menemukan bahwa untuk bisa bertumbuh dalam relasi dengan Kristus, dimulai dari menerima Kristus serta berjalan di dalam Kristus, dan dilanjutkan dengan bertambah teguh di dalam Kristus dengan indikator berakar dalam Kristus, dibangun di atas Kristus, bertumbuh dalam iman kepada Kristus dan hati yang selalu bersyukur.
\end{abstract}

Kata Kunci: Bertumbuh, relasi, Kristus, Kolose.

\begin{abstract}
In this article, the author made a study of growing in a relationship with Christ according to Colossians 2:6-7. This article began from the author's concern about the shallow condition of Christian faith at this time, wich can easily be sucked in by the false teachings that are increasingly prevalent in social media. The rapid development of science and technology allows believers to obtain various teachings that have existed ind social media that are not in accordance with the word of God. The purpose of this article is to present the results of study on how believers grow in their relationship with Christ. This article analyzes growing in a relationship with Christ according to Colossians 2:6-7, so that Paul's counsel to the Colossians can also be carried out by the church today. The method used by the author in this article is a qualitative research method with a ecegetical approach. The analysis process carried out by the author was exeggesis the biblical text and analyze reliable secondary sources to produce accountable studies. The results of this study found that to be able to grow in a relationship with Christ, you must start from accepting Christ and walking in Christ, and continue with being stronger in Christ with indicators of being rooted in Christ, being built on Christ, being growth in faith in Christ and a heart that always grateful.
\end{abstract}


Keywords: Gowing, relationship, Christ, Colossians.

\section{Pendahuluan}

Tulisan ini merupakan suatu kajian tentang bertumbuh dalam relasi dengan Kristus berdasarkan Kolose 2:6-7. Pesan utama Paulus dalam teks itu adalah setiap orang percaya harus terus bertumbuh di dalam relasi dengan Kristus. Bagi Paulus, bertumbuh dalam relasi dengan Kristus sangat penting, karena pada dasarnya relasi manusia yang sebelumnya rusak antara Allah dan manusia, kini dipulihkan oleh pengorbanan Kristus Yesus. Manusia menerima itu semua sebagai wahyu yang nyata dalam hidupnya dan memformulasikannya ke dalam bentukbentuk pernyataan kesungguhan imannya akan Kristus Yesus. Kesungguhan iman tersebut nampak di dalam kehidupan orang Kristen yang selalu menunjukkan ciri khasnya berdasarkan kitab suci dan ajaran rasuli.

Dasar-dasar inilah yang menjadi awal mula tumbuh kembangnya benih iman yang ada di dalam diri setiap umat saat ini, berbuah dalam hidup yang diekspresikan secara personal dan komunal. Iman semacam ini merupakan beriman teguh atas dasar relasi yang intens dengan Kristus secara pribadi. Disebut sebagai relasi pribadi karena tidak terikat oleh ruang dan waktu serta tata cara ritual resmi, sebagaimana yang dilakukan secara komunal. ${ }^{1}$

Berdasarkan penjelasan di atas, penulis melihat bahwa ada hal penting mengapa Paulus mendorong jemaat di Kolose untuk bertumbuh dalam relasi dengan Kritus, karena jemaat pada saat itu diperhadapkan suatu ajaran-ajaran baru yang menyesatkan dan membelokkan iman mereka kepada Kritus

\footnotetext{
${ }^{1}$ Antonius Atosokhi Gea, Character Building III (Jakarta: PT Elex Media Komputindo, 2004), 163.
}

(ay.8). Kasus-kasus seperti di atas dialami juga oleh orang-orang Kristen saat ini. Oleh sebab itu, dalam tulisan ini penulis akan menguraikan fakta-fakta tersebut secara empiris.

Pengajaran-pengajaran sesat ini sangat gencar untuk melemahkan iman orang percaya yang disebarkan melalui media-media sosial. Akibatnya dari pengajaran-pengajaran sesat ini sangat meresahkan kehidupan Kekristenan. Selain itu, ajaran-ajaran sesat ini tidak hanya datang dari luar Kekristenan (eksternal), tetapi ajaran-ajaran tersebut datang dari dalam Kristen (internal) yakni orang-orang yang hanya mengajarkan sesuai dengan kehendak dan pengertiannya sendiri dan tidak sesuai firman Tuhan. Juanda dan Zevania menyatakan bahwa keberadaan ajaran sesat adalah untuk melemahkan iman kepada ajaran Alkitab yang sesungguhnya. ${ }^{2}$ Oleh sebab itu, hal ini merupakan masalah serius yang harus ditanggapi oleh Kekristenan. Morris Phillips Takaliuang menjelaskan bahwa ajaran sesat merupakan bahaya, ancaman dan rongrongan yang merusak ajaran yang benar, menyesatkan pikiran dan merusak iman. ${ }^{3}$

Perkembangan teknologi yang pesat saat ini merupakan salah satu penyebabnya, karena dapat memudahkan orang Kristen mengakses berbagai ajaran apa saja dan di mana saja, baik melalui

\footnotetext{
${ }^{2}$ Judana dan Zevania Venda, "Menghadapi Ajaran Sesat Studi Jemaat Efesus Menurut 1 Timotius 4:6-16", KERUSSO, Vol. 1 No. 1 (2019): 5. http://jurnal.sttii-

surabaya.ac.id/index.php/Kerusso/issue/view/9.

${ }^{3}$ Morris Phillips Takaliuang, "View of Ancaman Ajaran Sesat di Lingkungan Kekristenan: Suatu Pelajaran Bagi Gereja-Gereja di Indonesia", Missio Ecclesiae Vol. 9 No. 1 (2020): 132. https://jurnal.i3batu.ac.id/index.php/me/article/vie w/115/90 [accessed 23 September 2020].
} 
Youtube, Facebook, Instagram, dan lain sebagainya. Hal ini tidak dapat dipungkiri, bahwa teknologi berperan besar dalam proses penyebaran serta akses berbagai informasi sekarang ini. ${ }^{4}$ Hal ini dapat terlihat di tayangantayangan di berbagai media sosial, seperti khotbah-khotbah yang tidak sesuai kebenaran firman. Hengki Wijaya menyatakan bahwa fenomena yang sering terjadi sekarang ini ialah adanya pengkhotbah yang hanya pandai berbicara, ada yang berkhotbah tidak sesuai nats yang Alkitab maksudkan, ada juga yang instan mengambil dari internet tanpa mempelajari kebenaran firman Tuhan. ${ }^{5}$ Sebagai contoh, baru-baru ini muncul mengenai adanya teori konspirasi di balik virus Covid-19 yang mengkaitkan vaksin dengan 5G dan 666 yang telah dibahas dalam artikel yang dituli Endah Christina. ${ }^{6}$ Tentu ajaran-ajaran semacam ini begitu membingungkan bahkan bisa membahayakan jemaat awam. Bahkan Nova Ritonga dengan tegas mengatakan pengajaran-pengajaran sesat seperti ini bisa mengakibatkan adanya orang percaya yang disesatkan dan meninggalkan imannya semula. ${ }^{7}$ Oleh sebab itu, setiap orang percaya perlu bertumbuh di dalam

\footnotetext{
${ }^{4}$ Talizaro Tafonao, "Peranan Media Pembelajaran Dalam Meningkatkan Minat Belajar Mahasiswa", Jurnal Komunikasi Pendidikan, Vol. 2 No. 2 (2018):

http://journal.univetbantara.ac.id/index.php/komdi k/article/view/113/0

${ }^{5}$ Hengki Wijaya, Khotbah Untuk Pendidikan Warga Jemaat (Makassar: STT Jaffray, 2018), 12.

${ }^{6}$ Endah Christina, "Pdanemi Covid-19 Adalah 666?", Logia: Jurnal Teologi Pentakosta, Vol. 1 No. 2 (2020), 1-22. http://sttberea.ac.id/ejournal/index.php/logia/article/view/40

${ }^{7}$ Nova Ritonga, "Teologi Sebagai Ldanasan Bagi Gereja dalam Mengembangkan Pendidikan Agama Kristen", Jurnal Shanan, Vol. 4 No. 1 (2020): 23. http://ejournal.uki.ac.id/index.php/shan/article/vie w/1766/1352.
}

relasi dengan Tuhan, sehingga dapat menyaring berbagai ajaran yang diterima dan tidak mudah disesatkan.

Berdasarkan pokok persoalan di atas, maka penulis mengkaji mengenai bertumbuh dalam relasi dengan Kristus berdasarkan Kolose 2:6-7. Sebagaimana nasihat dari rasul Paulus kepada jemaat di Kolose, maka penulis merumuskan sebuah rumusan, bahwa setiap orang percaya masa kini perlu untuk bertumbuh dalam relasi dengan Kristus, sehingga dengan demikian dapat memiliki kedewasaan iman, yang bisa memilah mana ajaran yang sesuai dengan kebenaran firman Tuhan, dan mana ajaran yang membawa kepada kesesatan.

Beberapa tulisan terdahulu pernah membahas topik yang serupa dengan topik yang penulis paparkan. Namun ada perbedaan yang jelas antara tulisantulisan terdahulu dengan tulisan penulis saat ini. Di antaranya ada Juanda dan Zevania yang menulis artikel "Menghadapi Ajaran Sesat - Studi Jemaat Efesus Menurut 1 Timotius 4:6-16,"8 perbedaan dengan tulisan penulis terletak pada ayat yang menjadi landasan tulisan yang tentu akan semakin memperkaya pemahaman bagi kemajuan dunia pendidikan Kristen. Selain itu ada juga Endah Christina yang menulis di Jurnal Logia dengan judul artikel "Pandemi Covid-19 adalah 666?"9 dengan menyoroti teori-teori menyesatkan yang hadir seiring peristiwa Covid-19, dengan demikian mengajak orang Kristus mengkritisi dan menganalisis berita-berita tersebut. Berbeda dengan tulisan ini, penulis memaparkan bagaimana cara

\footnotetext{
${ }^{8}$ Judana dan Zevania Venda, "Menghadapi Ajaran Sesat Studi Jemaat Efesus Menurut 1 Timotius 4:6-16", KERUSSO, Vol. 1 No. 1 (2019): 1-5. http://jurnal.sttii-

surabaya.ac.id/index.php/Kerusso/issue/view/9.

${ }^{9}$ Christina, "Pdanemi Covid-19 Adalah 666?", 122.
} 
orang percaya bisa bertumbuh di dalam relasi dengan Kristus, yang memampukan untuk menghadapi ajaran-ajaran sesat tersebut.

Tujuan dari penulisan ini ialah menyuguhkan hasil kajian mengenai bagaimana cara orang percaya bertumbuh dalam relasi dengan Kristus berdasarkan Kolose 2:6-7, sehingga dapat memiliki iman yang kuat untuk mampu tetap berada dalam ajaran Kristus dan tidak tergoyahkan oleh ajaran-ajaran sesat.

\section{Metode}

Metode yang digunakan oleh penulis adalah metode penelitian kualitatif dengan pendekatan kajian eksegese. Eksegese merupakan penerapan dari hermeneutik untuk memperoleh maksud penulis dari teks bahasa aslinya, sehingga teks tersebut dapat dimengerti pembaca masa kini. ${ }^{10}$ Sehingga dengan demikian dapat ditarik relevansinya untuk situasi masa kini. Penulis melakukan proses analisis terhadap Alkitab sebagai sumber utama, serta berbagai sumber kepustakaan yang terpercaya untuk menghasilkan kajian yang dapat dipertanggungjawabkan.

\section{Pembahasan}

Surat Kolose memberikan kepada pembaca masa kini sekilas mengenai situasi dan kondisi dunia gereja abad pertama, tentang bagaimana orang percaya mempraktikkan iman mereka dalam berbagai latar kehidupan. Pada saat yang sama, terlihat juga gereja bergumul dengan pertanyaan tentang praktik keagamaan mana yang relevan dengan

\footnotetext{
${ }^{10}$ Deora Westa Purba, "Hermeneutika Sebagai Metode Pendekatan Dalam Teologi", Regula Fidei: Jurnal Pendidikan Agama Kristen, 3.1 (2018), 527.
}

iman baru yang dimiliki anggotanya. ${ }^{11}$ Kebingungan semakin bertambah dengan adanya para bidat yang mengacau ajaran yang sesungguhnya. Surat Kolose merupakan jawaban atas semua kebingungan tersebut. Dari sudut pandang apa pun yang dilihat oleh setiap pembaca sekarang ini, Kolose selalu up to date. Meskipun ditulis kurang lebih 2.000 tahun yang lalu, namun pesannya abadi berbicara kepada dilema yang terjadi harihari ini.

Surat Kolose menekankan relasi pribadi antara Kristus dan Jemaat-Nya. ${ }^{12}$ Oleh sebab itu Paulus menasihati jemaat di Kolose untuk menjalankan hidup yang sesuai dengan Tuhan Yesus Kristus yang telah mereka kenal melalui pengajaran rasuli. Bukan malah mendengar dan mengikuti ajaran-ajaran sesat dari para bidat. Paulus dalam suratnya meminta agar orang percaya untuk bertumbuh dalam relasi dengan Kristus. Bertumbuh dalam relasi dengan Kristus berdasarkan Kolose 2:6-7 penulis paparkan sebagai berikut:

\section{A. Menerima Kristus (Ay. 6)}

1. Kolose 2:6a "Kamu telah menerima Kristus Yesus ..."

Paulus menyatakan identitas jemaat Kolose dengan jelas, bahwa jemaat Kolose sudah/telah menerima Kristus. Hal ini juga Paulus ungkapkan di salam pembukannya bahwa surat ini memang ditujukan "kepada orang-orang kudus dan yang percaya dalam Kristus" yang ada di Kolose (1:2). Selanjutnya Paulus menguraikan bahwa jemaat Kolose menerima Kristus setelah mendengar pemberitaan dari Epafras (1:7)

\footnotetext{
${ }^{11}$ Jerry L. Sumney, Colossians: A Commentary (London: Westminster John Knox Press, 2008), 1.

${ }^{12}$ Watchman Nee, Kebenaran Yang Memiliki Dua Sisi (Surabaya: Yayasan Perpustakaan Injil Indonesia, 2019), 1.
} 
teman sepelayanan Paulus yang dikasihi dan setia.

Istilah "menerima" (Yunani:

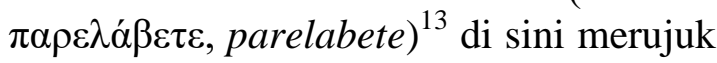
kepada tradisi (paradosis) Injil Kristen yang sudah dikembangkan melalui ajaranajaran rasul (1:7). Istilah ini berasal dari konsep korespondensi dalam tradisi Rabbinik, yaitu qibel atau masar, yang artinya menerima, menyetujui, dan memindahkan. Misalnya tradisi pewarisan Taurat, Musa menerima Taurat di Gunung Sinai dan meneruskannya kepada Yosua, Yosua kepada para tua-tua Israel, lalu ke para nabi, dan kepada imam besar di Sinagoge. Dalam jemaat Kolose, tradisi pengajaran itu tetap berjalan namun terjadi pergeseran substansi ajaran menjadi berita Injil. Pusat pemberitaan tradisi Kristen ialah adanya konfesi bahwa "Yesus itu Tuhan" (

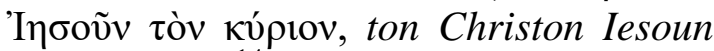
ton Kurion). ${ }^{14}$ Dan melalui frasa ini Paulus sekaligus mengingatkan jemaat Kolose, sekalipun jemaat telah mengakui Yesus itu Tuhan, mereka juga harus tetap berlaku konsekuen terhadap iman mereka kepada Kristus yang telah mereka terima sebagai Tuhan dan Juruselamat. ${ }^{15}$ Jemaat dituntut untuk hidup seiras dengan Kristus yang telah mereka percayai.

Menerima Kristus merupakan syarat pertama dan utama untuk seseorang bisa menjalin relasi dengan Kristus. Sebagaimana yang dikatakan Nadeak dan Hidayat bahwa relasi dengan Kristus dimulai ketika menerima anugerah keselamatan dari Yesus Kristus, dengan cara menerima Kristus sebagai

\footnotetext{
${ }^{13}$ BibleWorks 10.

${ }^{14}$ BibleWorks 10.

${ }^{15}$ Reymond Pdanapotan Sianturi, "Memaknai Pleroma (Kepenuhan Ke-Allahan) Kristus dalam Relasi Interreligius di Indonesia - Tafsiran Kontekstual Atas Kolose 2 : 6-15", Gema Teologi: Jurnal Teologi Kontekstual, Vol. 37 No. 1 (2013): 13.
}

satu-satunya Tuhan dan Juruselamat. ${ }^{16}$ Inilah yang menjadi ucapan syukur Paulus, sebab mereka dahulu adalah umat yang jauh dari Allah dan yang memusuhi Alah, namun telah diperdamaikan (1:2122). Manusia yang sebelumnya jauh dari Allah bahkan memusuhi Allah, kini telah diperdamaikan oleh perngorbanan Yesus Kristus di atas kayu salib di bukit Golgota. Hubungan yang dahulu telah rusak kini dipulihkan oleh Kristus ketika manusia menerima Kristus sebagai Tuhan dan Juruselamat.

Menerima Kristus berarti percaya dan menerima anugerah keselamatan dari Allah di dalam Kristus Yesus. Percaya atau beriman adalah penyerahan diri secara pribadi sepenuhnya kepada Allah dan menerima kebenaran objektif yang diwahyukan dan yang dipercaya. Beriman kepada Kristus merupakan tindakan nyata yang dilakukan oleh manusia dengan pertolongan Roh Kudus. Hal ini adalah tanggapan yang bebas, bertanggung jawab dan utuh dari manusia itu sendiri.

Dalam Injil Yohanes 3:16, tercatat kerinduan hati Bapa di sorga, yaitu agar setiap orang yang percaya kepada Yesus beroleh keselamatan. Keselamatan ialah inisiatif dari Allah sendiri yang telah mengutus Yesus Kristus Sang Juruselamat tersebut. Ada satu sifat Allah yang sangat menonjol di dalam peranNya sebagai Sang Inisiator Keselamatan, yaitu anugerah atau kasih karunia (pemberian cuma-cuma). ${ }^{17}$ Anugerah

\footnotetext{
${ }^{16}$ Erni Hanna Nadeak dan Dylmoon Hidayat, "Karakteristik Pendidikan yang Menebus di Suatu Sekolah Kristen [The Characteristics of Redemptive Education In a Christian School]", Polyglot: Jurnal Ilmiah, Vol. 13 No. 2 (2017): 89. https://doi.org/10.19166/pji.v13i2.439.

${ }^{17}$ Aya Susanti, "Relevansi Finalitas Kristus di Tengah-Tengah Arus Pluralisme dan Pluralitas Masyarakat Indonesia", Evangelikal: Jurnal Teologi Injili dan Pembinaan Warga Jemaat, Vol. $1 \quad$ No. $\quad 1 \quad$ (2017): 85.
} 
merupakan sesuatu yang tidak disangkasangka atau sesuatu yang tidak layak diterima namun diberi dengan tidak dibayar. Inilah anugerah Allah kepada manusia, yaitu Allah melayakkan manusia yang telah jatuh ke dalam dosa dan selalu menjauh dari Allah, supaya bisa berbalik kembali kepada Allah, menjalin relasi dengan Allah, melalui pengorbanan Kristus. Manusia akan menerima anugerah ini ketika manusia menerima Kristus.

Hal inilah yang harus diajarkan kepada jemaat masa kini oleh para rohaniwan dan pendidik agama Kristen, bahwa keselamatan yang dari Allah, hanya dapat diterima di dalam Yesus. Menerima Kristus sebagai Tuhan dan Juruselamat merupakan anugerah untuk bisa menjalin relasi dengan Kristus yang adalah Allah sebagai inti dari Kekristenan.

2. Kolose $2: 6 b$ “....Karena itu hendaklah hidupmu tetap (berjalan) di dalam Dia"

Terjemahan LAI dalam bahasa Indonesia untuk frasa Kolose 2:6b ini adalah "...hendaklah hidupmu tetap di dalam Dia." Namun terjemahan harafiah dari teks asli cukup membantu dalam memberikan pemahaman yang spesifik. Dalam teks asli dari frasa ini adalah $\dot{\varepsilon} v$ $\alpha \nu \tilde{\omega} \pi \varepsilon \rho \imath \pi \alpha \tau \varepsilon i \tau \varepsilon,{ }^{18}$ bila secara harafiah, terjemahan frasa ini adalah “...berjalanlah di dalam Dia”. James Dunn juga memiliki terjemahan yang hampir serupa untuk menerjemahkan frasa en auto peripateite, yaitu "...berjalan bersama...". ${ }^{19}$ Hal ini memberi pengertian bahwa perjalanan

https://journal.sttsimpson.ac.id/index.php/EJTI/art icle/view/65/45

${ }^{18}$ BibleWorks 10.

${ }^{19}$ James D. G. Dunn, The Epistles to the Colossians dan to Philemon (USA: Wm. B. Eerdmans Publishing Co., 2014), 138. pengikutan orang percaya kepada Tuhan tidaklah sendiri, tetapi berjalan di dalam dan bersama dengan Tuhan. Karena jemaat Kolose telah menerima Kristus, maka Paulus menghendaki agar jemaat Kolose berjalan di dalam dan bersama dengan Kristus di dalam hidup mereka. Inilah relasi itu, yaitu orang percaya berjalan dalam kehendak Kristus yang sudah diterima, tidak lagi berjalan menurut kehendak diri sendiri, apalagi kehendak dari orang lain.

Penerjemahan menggunakan kata "tetap" dengan "berjalan" memiliki konotasi yang berbeda. Ketika berbicara mengenai "tetap" tentu memiliki arti tidak berpindah dan tanpa pergerakan atau pergeseran sedikit pun. Ketika berbicara mengenai berjalan, maka ada pergerakan yang terjadi. Kehidupan Kristen bukanlah kehidupan yang stagnan, tetapi kehidupan yang bergerak maju, mengarah kepada kesempurnaan dan keserupaan dengan Kristus. Yesus bukanlah pribadi yang hanya bisa memerintah tapi tidak melakukan. Yesus sendiri sudah menjadi jalan kepada Bapa, dan Yesus mau setiap orang bisa berjalan di dalam dan bersama dengan Dia sebagai contoh dan teladan yang sempurna. ${ }^{20}$

Guru-guru palsu yang mengajarkan ajaran-ajaran sumbang di jemaat Kolose ingin agar jemaat Kolose menerima tambahan-tambahan kepada Kristus. Mereka mengajarkan bahwa Yesus Kristus itu tidak lengkap, tidak unik, hanya salah satu manifestasi Allah, dan sungguh penting untuk mengenal dan melayani kuasa-kuasa ilahi yang lain agar dapat diselamatkan. Hal inilah yang membuat Paulus begitu menekankan

\footnotetext{
${ }^{20}$ Talizaro Tafonao, "Yesus Sebagai Guru Teladan Dalam Masyarkat Berdasarkan Perspektif Injil Matius", Khazanah Theologia, Vol. 2 No. 1 (2020):

57. https://journal.uinsgd.ac.id/index.php/kt/article/vie w/8390
} 
bahwa keselamatan hanya ada di dalam Yesus. Liem Khiem Yang menjelaskan bahwa frasa "...hendaklah hidupmu berjalan di dalam Dia" ini merupakan harapan Paulus agar jemaat berjalan dalam suatu garis tradisi Injil Yesus Kristus. Berjalan di dalam Injil Kristus ini memiliki arti bahwa jemaat Kolose harus hidup sesuai dengan Kabar Baik (Injil) yang telah diberitakan Paulus selama ini, yaitu keselamatan hanya ada di dalam Yesus yang diberikan sebagai anugerah dan diterima dengan iman oleh manusia. ${ }^{21}$ Keselamatan ini bukan dari perbuatan dan usaha manusia, tetapi anugerah Allah. Dan keselamatan itu telah diterima oleh jemaat Kolose ketika mereka telah menerima Kristus sebagai Tuhan dan Juruselamat.

Inilah yang harus dipahami oleh orang percaya masa kini, bahwa setiap orang yang sudah menerima Kristus, harus benar-benar berjalan di dalam Kristus. Berjalan di dalam Kristus artinya hidup sesuai dengan Injil Kristus, bahwa keselamatan itu hanya ada di dalam Kristus, bukan karena tambahantambahan perbuatan yang lain. Tidak lagi hidup dengan paradigm bahwa dengan berbuat hal-hal yang terkait tradisi keagamaan untuk diselamatkan. Hanya Kristus Juruselamat, tidak perlu tambahan-tambahan yang lain.

\section{B. Bertambah teguh di dalam Kristus (Ay. 7)}

1. Berakar di dalam Kristus: "Hendaklah kamu berakar di dalam Dia..."

\begin{tabular}{lccr}
\multicolumn{2}{c}{ Berakar di } & dalam & Kristus \\
merupakan langkah & awal & untuk \\
bertambah teguh di & dalam & Kristus. \\
Terjemahan King & James & Version \\
menerjemahkan kata "berakar" & dengan
\end{tabular}

${ }^{21}$ Susanti, "Relevansi Finalitas Kristus...", 93. kata "rooted" yang secara harafiah berarti penyebab pengambilan nutrisi, memperkuat dengan akar, untuk menegaskan. $^{22}$ Berakar di dalam Kristus berarti terus menerus menutrisi diri, memperkuat diri, dan semakin menegaskan diri sebagai pribadi yang sudah menerima Kristus. Paulus menggambarkan Kekristenan seperti tanaman dan Kristus seperti tanahnya. Kekristenan perlu berakar ada Kristus, sama seperti tanaman yang tidak hanya bertumbuh ke atas tetapi juga bertumbuh ke bawah.

Untuk tujuan menutrisi iman, menguatkan iman dan menegaskan lagi keyakinan akan iman kepada Kristus yang telah diterima sebagai Tuhan dan Juruselamat, maka setiap orang percaya perlu memberi makan kerohaniannya dengan makanan yang bernutrisi. Nutrisi iman ini adalah firman Tuhan, baik yang didengar maupun yang dibaca, dipelajari dan dipahami.

Kuasa dari firman Tuhan sangat besar, petunjuk hidup orang percaya ada di dalamnya dan selalu relevan di segala zaman. ${ }^{23}$ Paulus dalam 2 Timotius 3:16 menyatakan bahwa Kitab suci itu bermanaat untuk mengajar, menyatakan kesalahan, memperbaiki kelakuan dan untuk mendidik orang dalam kebenaran. Oleh sebab itu setiap orang percaya wajib untuk membaca dan mempelajari firman Tuhan. Berakar di dalam Kristus ialah menutrisi iman secara terus menerus dengan cara tekun membaca Alkitab.

Para pemimpin gereja dan pendidik agama Kristen sangat perlu untuk memberi makanan yang bernutrisi bagi iman umat percaya. Namun tidak

\footnotetext{
${ }^{22}$ BibleWorks 10.

${ }^{23}$ Stimson Hutagalung dan Rolyana Ferinia, "Menjelajahi Spiritualitas Milenial: Apakah Membaca Alkitab, Berdoa, dan Menghormati Ibadah di Gereja Menurun?", Jurnal Teruna Bakti, Vol. 2 No. 2 (2020): 102.
} 
berhenti sampai di situ saja. Sebagai pemimpin dan pendidik Kristen, perlu untuk mengajarkan jemaat agar bisa menutrisi iman secara mandiri, yaitu dengan membaca dan mempelajari firman Tuhan. Jemaat harus diajarkan bahwa membaca Alkitab tidak hanya di gereja, tetapi juga di rumah masing-masing. Artinya tidak hanya mendengar apa yang dikatakan para pengkhotbah saja, tetapi juga mendisiplinkan diri untuk membaca firman setiap hari, mempelajari firman sebagai nutrisi iman. Hanya dengan cara demikian orang percaya dapat terus mengakarkan imannya dengan kuat di dalam Kristus.

2. Dibangun di atas Kristus: “...dan dibangun di atas Dia..."

Iman yang dibangun di atas Kristus merupakan iman yang bertindak bukan karena apa kata dunia, tetapi apa kata Kristus. Kekristenan merupakan sekumpulan umat yang percaya dan mengikuti Yesus. Kepercayaan dan pengikutan serta menjadi murid Yesus ini dibagun di atas penegasan besar bahwa Yesus Kristus adalah Allah yang datang dari Surga untuk turun ke bumi, menjadi manusia untuk menyelamatkan manusia. Dibangun di atas Kristus memiliki arti hidup yang dibangun atas dasar normanorma Allah, yaitu norma kasih. Hidup dalam norma-norma Allah seperti yang dijelaskan juga oleh Paulus secara singkat memiliki konotasi "apa yang diberi" bukan "apa yang diterima", bukan untuk "mencari berkat" tetapi untuk "menjadi berkat". 24

Jika agama lain menyampaikan manusia yang mencoba mendaki gunung di mana Allah berada (tidak mungkin), maka Kekristenan mewahyukan

\footnotetext{
${ }^{24}$ Eka Darmaputera, Tegak, Sebab Didirikan Di Atas Batu, BPK Gunung Mulia (Jakarta: BPK Gunung Mulia, 2008), 3.
}

bagaimana Allah telah turun dari puncak tertinggi di dalam Kristus, dan tinggal bersama dengan manusia serta merasakan apa yang manusia rasakan (mungkin). Yesus sebagai teladan sudah melakukan sesuatu hal yang luar biasa, yaitu dari tempat yang tinggi turun ke bawah demi kepentingan manusia.

Iman yang dibangun di atas Kristus ini menjadi modal awal bagi Kekristenan yang benar. Sebab Kekristenan yang benar bukanlah iman yang dibangun atas dasar usaha manusia, tetapi iman yang dilandasi pada korban Kristus yang telah mengorbankan diriNya bagi keselamatan manusia sebagai bukti kasih-Nya. ${ }^{25}$ Paulus menghendaki agar jemaat membangun Kekristenan mereka di atas dasar kasih Kristus. Sehingga dasar dari tindakan-tindakan Kekristenan mereka adalah tindakantindakan yang didasarkan pada kasih. Melakukan sesuatu bukan karena ingin menerima keselamatan lagi, tetapi melakukan sesuatu karena sudah menerima. Mengasihi sesama bukan untuk menerima keselamatan, tetapi mengasihi sesama karena sudah lebih dahulu merasakan kasih itu.

Jemaat masa kini perlu diajarkan bahwa mengasihi sesama bukan untuk mengharapkan dikasihi kembali, bukan memilihi-milih orang yang dikasihi, bukan juga untuk mendapatkan keselamatan. Tetapi mengasihi sesama untuk menyatakan kasih Kristus kepada sesama, menghadirkan kasih Kristus bagi dunia. Dimulai dari hal-hal sederhana, memberi tanpa mengharapkan imbalan, mengampuni sesama yang bersalah, melayani Tuhan dengan sungguh dan lain sebagainya.

3. Bertumbuh di dalam iman kepada Kristus: "...hendaklah kamu

\footnotetext{
${ }^{25}$ Mark Stibbe, User's Guide to Christian Belief (Oxford: Lion Hudson PLC, 2007), 61.
} 
bertambah teguh dalam iman yang telah diajarkan kepadamu..."

Setelah memberikan kepastian keselamatan bagi mereka yang menerimaNya, Allah memiliki tujuan selanjutnya bagi orang percaya. Tujuan Allah berikutnya bagi setiap orang yang telah menerima Kristus ialah agar menjadi dewasa di dalam iman kepada Kristus melalui setiap pengajaran rasuli yang diterima. Kedewasaan iman memampukan orang Kristen untuk tidak mudah diombang-ambingkan oleh bermacam-macam pengajaran, permainan palsu dan kesesatan manusia. Kedewasan iman adalah sasaran yang harus dicapai oleh setiap orang percaya.

Iman yang bertambah teguh dan kuat haruslah iman yang bertumbuh. Iman tidak hanya digunakan untuk percaya di awal semata, tetapi perlu diteruskan dengan ketekunan dan ketaatan di setiap tahap kehidupan Kekristenan. Paulus menggunakan kata $\beta \varepsilon \beta \alpha \imath o v ́ \mu \varepsilon v o r$ (confirm, secure, establish, be strenghthened $)^{26}$ yang bisa diartikan sebagai konfirmasi, mengamankan, menstabilkan, dan menjadi kuat. Iman jemaat Kolose harus dikonfirmasi ulang untuk meneguhkan, harus diamankan dari ajaran-ajaran palsu, harus stabil serta kuat dan teguh sesuai dengan apa yang telah diajarkan kepada mereka, sehingga tidak mudah diombang-ambingkan.

Paulus sangat berharap agar jemaat yang telah berakar di dalam Kristus, dibangun di atas Kristus, harus terus bertambah teguh di dalam Kristus. Iman hanya bisa bertumbuh melalui firman Tuhan. Tumbuh-tumbuhan bertumbuh bukan karena kekuatiran atau usaha mereka sendiri, tetapi hanyalah dengan menerima apa yang telah Allah sediakan. Firman Tuhan telah Allah sediakan bagi pertumbuhan iman orang

${ }^{26}$ BibleWorks 10. percaya. Alkitab adalah makanan rohani yang sangat sehat. Dengan mengerti, mempercayai dan melakukannya seorang Kristen akan bertumbuh secara sehat dan sempurna. Tidak ada sarana lain yang olehnya seorang Kristen memperoleh makanan rohani yang sehat dan bergizi kecuali firman Allah. ${ }^{27}$ Pada tahap ini, iman yang bertumbuh tidak hanya membaca dan mempelajari firman, tetapi juga meyakini, mempercayai sepenuhnya firman yang sudah dibaca dan dipelajari, serta melakukannya.

Selain di Kolose 2:7 ini, Paulus kerap kali menggunakan istilah "bertambah teguh" untuk menekankan keteguhan dan kekokohan. Tidak menunjuk pada pola ajaran atau kepercayaan, melainkan hubungan yang hidup kepada Yesus sebagai Tuhan. Ungkapan "hendaklah kamu bertambah teguh" akan lebih mudah dimengerti jika disusun dalam terjemahan: "Hendaklah kepercayaanmu kepada Kristus makin lama makin teguh" atau boleh juga diungkapkan berupa pengikraran, misalnya "Hendaklah keyakinanmu semakin tidak tergoyahkan". ${ }^{28}$ Terjemahan ini menunjukan suatu progres iman. Bertambah teguh merupakan keharusan bagi Kekristenan agar tidak mudah digoyahkan dengan pengajaranpengajaran yang tidak benar.

Oleh sebab itu, orang percaya harus dididik untuk jangan pernah merasa puas akan lamanya waktu mengikut Tuhan. Kebanggaan akan lamanya menjadi orang Kristen bisa saja menjadi celah tetapi biarlah setiap orang percaya terus memperkuat kepercayaannya

\footnotetext{
${ }^{27}$ Yusuf eko Basuki, Pertumbuhan Iman Yang Sempurna: Menumbuhkan Iman Sesuai Kehendak Allah (Yogyakarta: Garudhawacana, 2014), 119.

${ }^{28}$ Robert G. \& Eugene A. Nida Bratcher, Pedoman Penafsiran Alkitab: Surat-Surat Paulus Kepada Jemaat di Kolose dan Kepada Filemon (Jakarta: Yayasan Karunia Bakti Budaya Indonesia, 2019), 48.
} 
kepada Tuhan dan mengerjakan keselamatan yang dari pada Tuhan dengan sungguh. Sehingga mencapai tingkat kedewasaan yang tidak dapat tergoyahkan oleh apa pun juga.

4. Hati yang selalu bersyukur: “...dan hendaklah hatimu melimpah dengan syukur."

Iman yang tetap kuat dan stabil di dalam kepercayaan kepada Kristus harus diejawantahkan dalam sikap hidup yang sesuai dengan apa yang diajarkan kepada mereka. Salah satu sikap hidup yang diinginkan Paulus untuk dilakukan oleh jemaat Kolose adalah hidup yang melimpah dengan syukur. Alasan ucapan syukur ini jelas, karena jemaat telah menerima Kristus, maka juga menerima kepastian jaminan keselamatan yang tidak dapat diberikan oleh dunia apalagi karena usaha manusia yang sia-sia.

Ucapan syukur ini adalah ucapan syukur yang melimpah, dalam teks asli, kata yang dipakai adalah $\pi \varepsilon p ı \sigma \sigma \varepsilon v ́ o v \tau \varepsilon \varsigma$. 29 Kata ini harus dinyatakan dengan tindakan nyata yang aktif meluap-luap dan terus menerus. Sebagai mana yang dinyatakan oleh William MacDonald, kata ini merupakan present active, sedang menunjuk kepada proses yang terjadi terus menerus secara berkelanjutan, yang diproduksi oleh Tuhan. ${ }^{30}$ Kehidupan Kristen adalah kehidupan yang terus menerus bersyukur kepada Allah atas kasih karunia-Nya di dalam Kristus. Hal ini diungkapkan oleh ketaatan dan ketekunan iman yang dilakukan dengan penuh sukacita. Mengenal Injil adalah sukacita yang tidak terkatakan dengan ucapan syukur karena Bapa telah melayakkan manusia menjadi bagian dari

\footnotetext{
${ }^{29}$ BibleWorks 10.

${ }^{30}$ William Macdonald, Believer's Bible Commentary: Letter to the Collosians (Nashville: Thomas Nelson's Publisher, 2015), 124.
}

Kerajaan Allah (1:10-12). Oleh sebab itu, jemaat Kolose perlu untuk memahami bahwa ketika mereka menerima Kristus, maka ada jaminan keselamatan yang datangnya hanya dari Kristus saja, dan tidak bisa dunia berikan.

Dengan demikian, setiap orang percaya ketika sudah menerima Yesus, diharapkan dapat merasakan bahwa Yesus adalah harta yang sangat berharga dalam hidup mereka, melebihi apa pun yang ada di dunia, sehingga dapat bersyukur dalam keadaan apa pun, susah atau senang tetap bersyukur karena mereka memiliki Yesus. Tidak iri dengan apa yang orang lain miliki, dan orang lain capai.

\section{Kesimpulan}

Berdasarkan kajian dalam tulisan ini penulis hendak mengatakan bahwa bertumbuh dalam relasi dengan Kristus tidak cukup hanya dikhotbahkan oleh para Pendeta dan Penatua di gereja setiap minggu. Tata ibadah yang dilakukan setiap minggu tidak menjamin jemaat dapat bertumbuh dalam iman. Namun yang terpenting disini adalah pengajaran dan pendalaman Alkitab yang harus ditingkatkan, karena berdasarkan pemaparan dan bukti-bukti empiris dalam tulisan ini mengungkapkan bahwa salah satu persolan serius sehingga jemaat terpengaruh dengan ajaran-ajaran sesat dan tidak memiliki pondasi yang kuat karena lemahnya penggalian isi Alkitab dari para pemimpin dalam gereja.

Untuk bisa bertumbuh dalam relasi dengan Kristus, Kolose 2:6-7 menjelaskan bahwa orang percaya tidak boleh berhenti pada tahap menerima Kristus saja, melainkan harus terus bertambah teguh di dalam Kristus. Dimulai dari berakar di dalam Kristus yang artinya terus menutrisi iman dengan firman Tuhan, dibangun di atas Kristus dengan melakukan tindakan Kekristenan yang didasari oleh kasih, terus bertumbuh 
di dalam iman yang sudah dipelajari dan dipercayai dari firman Tuhan dengan melakukannya, serta hidup yang selalu bersyukur karena telah menerima keselamatan yang pasti dari Allah.

Kritiknya adalah hendaknya para pemimpin dan pendidik agama Kristen lebih bertanggung jawab dalam memperbaiki sistem pengajarannya selama ini yang tidak memberi nutrisi yang baik kepada umat, sehingga mengakibatkan lemahnya pemahaman umat tentang bertumbuh dalam relasi dengan Kristus sebagaimana penjelasan dalam karya tulis ini.

Tulisan ini bisa menjadi kontribusi kepada Pendeta, Penatua dan Guru Agama Kristen dalam meningkatkan kualitas pengajarannya berdasarkan Alkitab dalam memajukan pendidikan dan gereja pada umumnya sehingga studi analisis tentang bertumbuh dalam relasi dengan Kristus benar-benar bermanfaat dan menjadi referensi kepada peneliti berikutnya.

\section{Referensi}

Basuki, Yusuf eko, Pertumbuhan Iman Yang Sempurna: Menumbuhkan Iman Sesuai Kehendak Allah. Yogyakarta: Garudhawacana, 2014.

Bratcher, Robert G. \& Eugene A. Nida, Pedoman Penafsiran Alkitab: SuratSurat Paulus Kepada Jemaat Di Kolose Dan Kepada Filemon. Jakarta: Yayasan Karunia Bakti Budaya Indonesia, 2019.

Christina, Endah, "Pandemi Covid-19 Adalah 666?", Logia: Jurnal Teologi Pentakosta, 1 (2020): 1-23. http://sttberea.ac.id/ejournal/index.php/logia/article/view/ 40

Darmaputera, Eka, Tegak, Sebab Didirikan Di Atas Batu, BPK Gunung Mulia. Jakarta: BPK
Gunung Mulia, 2008.

Dunn, James D. G., The Epistles to the Colossians and to Philemon. USA: Wm. B. Eerdmans Publishing Co., 2014.

Gea, Antonius Atosokhi, Character Building III. Jakarta: PT Elex Media Komputindo, 2004.

Hutagalung, Stimson, and Rolyana Ferinia, "Menjelajahi Spiritualitas Milenial: Apakah Membaca Alkitab, Berdoa, dan Menghormati Ibadah di Gereja Menurun ?" Jurnal Teruna Bakti Vol. 2 No. 2 (2020): 97-111.

Juanda, \& Zevania Venda, "Menghadapi Ajaran Sesat Studi Jemaat Efesus Menurut 1 Timotius $4: 6-16 "$, KERUSSO, Vol. 1 No. 1 (2019): 1-5. http://jurnal.sttii-

surabaya.ac.id/index.php/Kerusso/issue/ view/9.

Macdonald, William, Believer's Bible Commentary: Letter to the Collosians. Nashville: Thomas Nelson's Publisher, 2015.

Nadeak, Erni Hanna, and Dylmoon Hidayat, "Karakteristik Pendidikan Yang Menebus Di Suatu Sekolah Kristen [The Characteristics of Redemptive Education In a Christian School]", Polyglot: Jurnal Ilmiah, Vol. 13 No. 2 (2017): 87-97. https://doi.org/10.19166/pji.v13i2.43 9

Nee, Watchman, Kebenaran Yang Memiliki Dua Sisi. Surabaya: Yayasan Perpustakaan Injil Indonesia, 2019.

Purba, Deora Westa, "Hermeneutika Sebagai Metode Pendekatan Dalam Teologi". Regula Fidei: Jurnal Pendidikan Agama Kristen, Vol. 3 No. 1 (2018): 527-530.

Ritonga, Nova, "Teologi Sebagai Landasan Bagi Gereja dalam 
Mengembangan Pendidikan Agama Kristen", Jurnal Shanan, Vol. 4 No. 1 (2020): 21-40. http://ejournal.uki.ac.id/index.php/sh an/article/view/1766/1352

Sianturi, Reymond Pandapotan, "Memaknai Pleroma (Kepenuhan Ke-Allahan) Kristus dalam Relasi Interreligius di Indonesia - Tafsiran Kontekstual Atas Kolose $2: 6-15 "$, Gema Teologi, 37.1 (2013): 1-28.

Stibbe, Mark, User's Guide to Christian Belief. Oxford: Lion Hudson PLC, 2007.

Sumney, Jerry L., Colossians: A Commentary. London: Westminster John Knox Press, 2008.

Susanti, Aya, "Relevansi Finalitas Kristus Di Tengah-Tengah Arus Pluralisme Dan Pluralitas Masyarakat Indonesia", Evangelikal: Jurnal Teologi Injili dan Pembinaan Warga Jemaat, Vol. 1 No. 1 (2017), 85-102. https://journal.sttsimpson.ac.id/index .php/EJTI/article/view/65/45
Tafonao, Talizaro, "Peranan Media Pembelajaran dalam Meningkatkan Minat Belajar Mahasiswa", Jurnal Komunikasi Pendidikan, Vol. 2 No. 2 (2018): 103-114. http://journal.univetbantara.ac.id/ind ex.php/komdik/article/view/113/0

Teladan dalam Masyarkat Berdasarkan Perspektif Injil Matius", Khazanah Theologia, Vol. 2 No. 1 (2020): 52-60. https://journal.uinsgd.ac.id/index.php /kt/article/view/8390

Takaliuang, Morris Phillips, "Ancaman Ajaran Sesat Di Lingkungan Kekristenan: Suatu Pelajaran bagi Gereja-gereja di Indonesia", Missio Ecclesiae Vol. 9 No. 1 (2020): 132156.

https://jurnal.i3batu.ac.id/index.php/ me/article/view/115/90

Wijaya, Hengki, Khotbah Untuk Pendidikan Warga Jemaat. Makassar: STT Jaffray, 2018. 